\title{
Internationales Trakl-Forum Salzburg
}

Im Rahmen der Salzburger Kulturvereinigung wird mit Unterstützung des Landes und der Stadt Salzburg das Internationale Trakl Forum Salzburg errichtet, das alle, an der Förderung und Vermittlung des Werkes Georg Trakls interessierten Persönlichkeiten und Fachleute zur Mitgliedschaft einlädt.

Ihre Mitarbeit haben bereits Vertreter des Germanistischen und des Historischen Instituts der Universität Salzburg, der Hochschule Mozarteum sowie des Otto Müller Verlages zugesagt.

Aufgabe des Internationalen Trakl Forums Salzburg wird sein:

a) Die Trakl Forschungs- und Gedenkstätte zu betreuen und auszubauen (Archiv, Bibliothek, Dokumentation).

b) Die wissenschaftliche Erforschung des Lebens und Werkes Georg Trakls unter Einbeziehung und Mitarbeit aller internationalen Fachleute zu gewährleisten.

c) Die Verbindung zur zeitgenössischen Literatur und zu anderen Kunstbereichen (wie z.B. Musik, Bildende und Darstellende Kunst) zu fördern.

d) Die Veröffentlichung der Werke Trakls sowie von Publikationen über den Dichter zu unterstützen und zu betreuen.

Die Geschäftsführung des Internationalen Trakl Forums Salzburg liegt bei Mag. Hans Weichselbaum, Kustos der Trakl Forschungs- und Gedenkstätte.

Anschrift: Internationales Trakl Forum, A-5020 Salzburg, Trakl-Haus, Waagplatz 1a, Telefon: 0662/845289. 